\title{
Original article: \\ The Word Cloud Analysis to Evaluate the Impact of COVID-19 on Environmental Professionals and Environmental Degree Holders: A PAN India Survey \\ Moharana Choudhury , *Srijan Goswami², Sougata Maity³, **Arghya Chakravorty4,
}

\begin{abstract}
:
Background: In addition to its impact on public health, COVID-19 has had a major impact on the Indian economy and the employment and education on the field of environmental sciences and engineering. This survey study has a mission to focus on how COVID-19 affects PAN India employment and the likely impact on education on the different environmental fields. Methodology: We have surveyed on PAN India basis by considering different working sectors on environmental field. In our survey, questionnaires circulated by email and different social media like Facebook, WhatsApp and their opinion have been analyzed by analyzing the frequency of the words from their texts / Word Cloud Analysis. Results and Conclusion: This survey report convey highest frequency of the word "life", "affecting", "Covid", "work" which is similar with "job", "time" "day", "home", "very", "lockdown" by all environmental professionals, students and researchers. This study suggests a need for more comprehensive and longitudinal evaluation of population needs, allowing the country to design holistic initiatives for affected people.
\end{abstract}

Keywords: COVID-19; Indian Context; Environmental Education; Environmental Employment, Environmental Degree Holders, Environmental Professionals.

Bangladesh Journal of Medical Science Vol. 20 No. 01 January’21. Page : 414-419 DOI: https://doi.org/10.3329/bjms.v20i2.51558

\section{Introduction}

A cluster of pneumonia incident was reported in the city of Wuhan, China, in the month of December, 2019. Some of the early cases of the transmission were reported to be started from seafood and live animal market in Wuhan ${ }^{1,2,3,4, \text { and } 5}$. Since then COVID 19 has become a common and most feared disease in the present time. The World Health Organization declared the outbreak a Public Health Emergency of International Concern on January 30, 2020 ${ }^{8}$. The impact of COVID-19 has been multiple and not only limited to the deterioration of heath. This pandemic and associated lockdown has also made a devastating impact on society, education, economy and several other aspects of life ${ }^{9}$.

According to joint study of the World Health The authors performed a general survey, intended to
Organization, International Labour Organization, Food and Agriculture Organization, International Fund for Agricultural Development around ten million people are at a risk of falling into extreme poverty ${ }^{5}$. As of October 13, 2020, the estimated numbers of undernourished people are around 690 million that is predicted to increase upto 132 million by the end of $2020^{10,11}$.According to UNICEF, more than one billion children are at risk of falling behind due to closure of educational institutions ${ }^{12}$.The COVID-19 pandemic has created the largest disruption in the history of education systems, affecting nearly 1.6 billion students in more than 190 countries and all continents. This has definitely negative impacts on

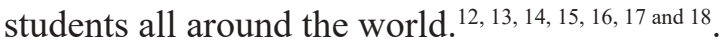

1. Moharana Choudhury, Voice of Environment (VoE), Guwahati, Assam, India

2. Srijan Goswami, Indian School of Complementary Therapy and Allied Sciences, Kolkata, India

3. Sougata Maity, Department of Statistics, Visva-Bharati University, Santiniketan, 731235- India

4. Arghya Chakravorty, School of Bio Sciences \& Technology, Vellore Institute of Technology, Vellore632014, India and R\&D Section, SANCHARAN (A Socio-Cultural Organization) 4289/2003, Agartala 799001, India

Correspondence to: Srijan Goswami, Indian School of Complementary Therapy and Allied Sciences, Kolkata, India. Email: srijangoswamiigmgs@gmail.com; arghya.kgp.AC@gmail.com 
understand the point of view of University students, Research-scholars, Professors, Assistant Professors, Associate Professors, Engineers, Manager, Teacher and other various sectors regarding the impact of disruption of day to day activities as a result of complete lockdown in India.

In this study a Covid-19 response dataset collected from various location in India. The participants were University student, Research-scholar, Professor, Assistant Professor, Associate Professor, Engineer, Managers, Teacher and other Govt. and NonGovt. sectors. The survey is made using Google Form containing most common question related to Covid-19, like How Covid-19 affecting your life?How Global Climate changes and Covid-19 interlinked?Share your opinion on current Scenario of Environmental Challenges and Opportunities? The present paper aim to analyze these datasets and conclude valid conclusion using various statistical tools.

\section{Methodology of the Survey}

\section{Reaching out to the Participants}

The survey was performed using online platform and social media. A set of questionnaire was created as Google Form and shared with various University students, Research-scholars, Professors, Engineers, Management Professionals, Teachers and Servicemen belonging to various Government and Non-Government sectors. The people shared their opinion using Facebook, Email, and Whatsapp.

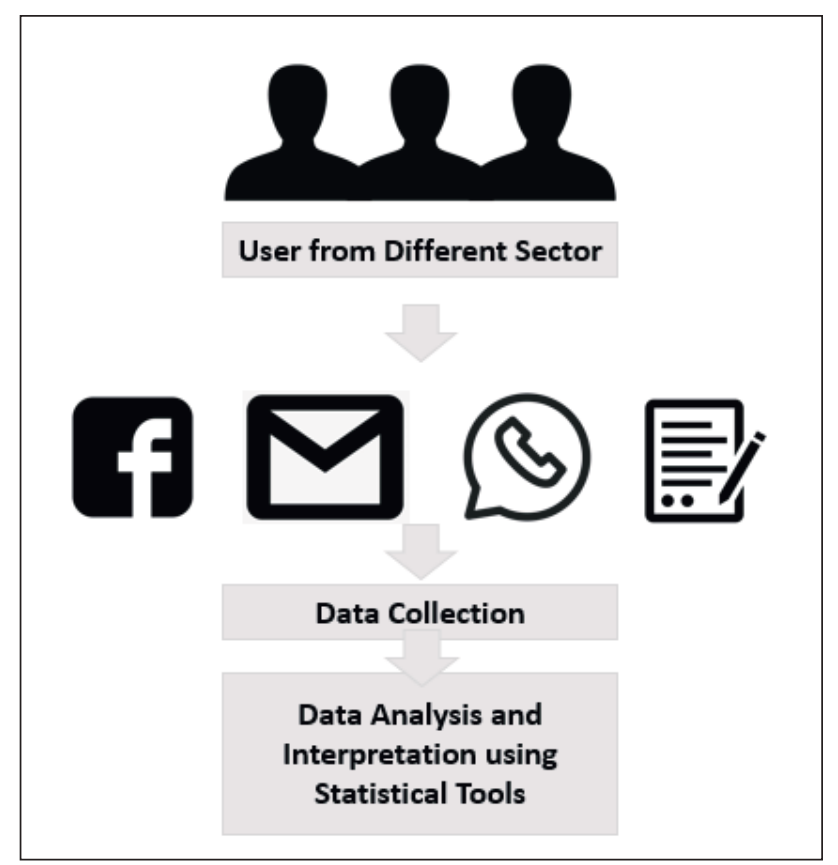

Figure 1. (Different medium of data collection)

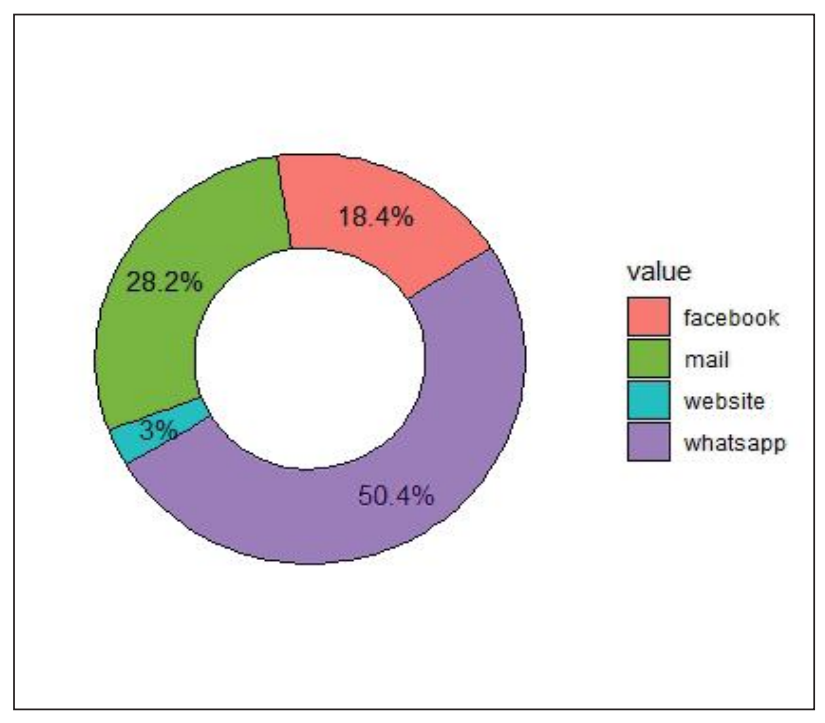

Figure 2 (Percentage of different medium chosen to answer)

The pie-chart shown as Figure 2, represents the percentage of the medium preferred for answering the questions. $50.4 \%$ people answered through Whatsapp, 28.2\% through E.mail, 18.4\% through Facebook and rest 3\% through other websites.

\section{Analysis of the Profession of the Participants}

Profession of the participant is one of the important parameter of this analysis. Various profession persons opinion in this Covid-19 questions various. This barchart clearly shows the fill-up percentage of various profession persons. $23.3 \%$ students fill-up this and it's larger than others. Then 21.5\% Research Scholar fill up this. $2.8 \%, 18.2 \%$ and $1.8 \%$ corresponding fill-up Professor, Assistant Professor and Associate Professor.

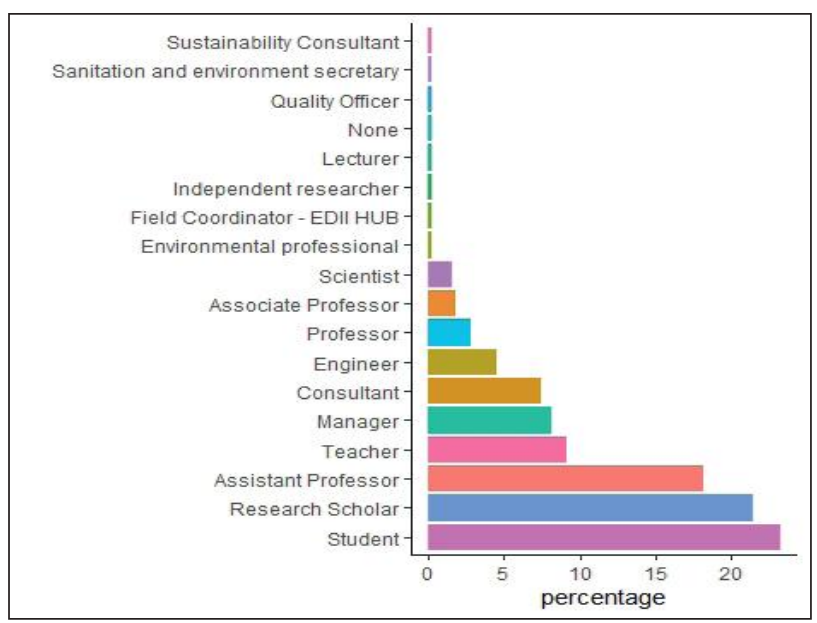

Figure 3 (Percentage of different professions in the survey) 


\section{Result and Discussion}

\section{How COVID 19 affecting your life?}

The pandemic, Covid-19 is a pandemic, has created global disorientation.

This brings out one of the valid and most important question, i.e. how does this situation affect day to day life. People belonging to various profession shared their experience and perspectives, which are presented as word cloud, emphasizing the important words. Highlighted and bigger word shows most frequently used word while sharing opinion. And other small highlighted word shows the less frequently used ones.

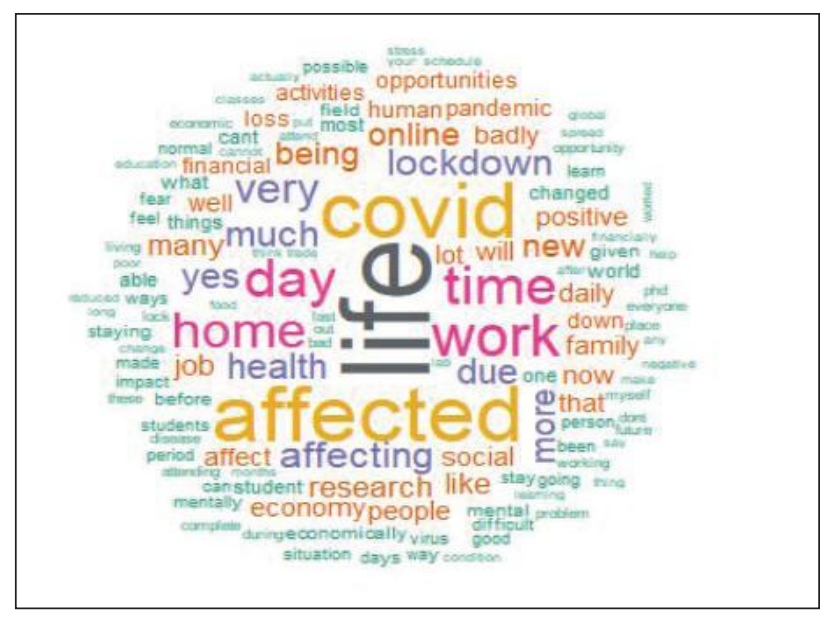

Figure 4. (Word Cloud Analysis of "How COVID 19 affecting your life?")

This bar plot (figure 5) and word cloud analysis shows most frequently used words and their frequency (times of repetition).Here life, affecting, Covid, work, time, day, home, health, job, research, lockdown very frequently used. This words gives a pre-image about this question (How Covid-19 affecting your life).

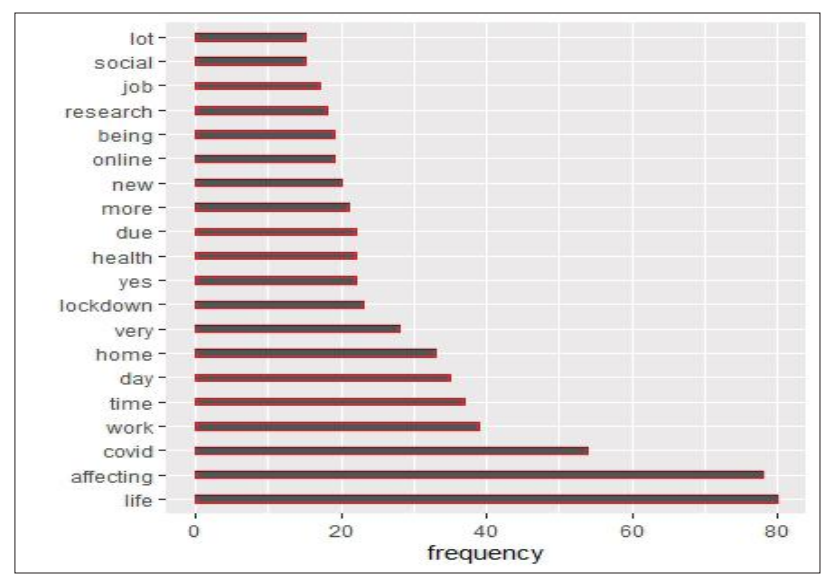

Figure 5. (Bar Plot Analysis of "How COVID 19 affecting your life?")

\section{Coefficient of variation:}

For this text-analysis, length of text play very important role. How many letter a person used for answering a question.

Consistency gives better result than and education inconsistence. A set of response in a particular profession use approximately same number of letters for answer a particular question that imply consistency.

Large number of response gives better consistency this is not true, Coefficient of variation (cv) measure the consistency.

$\mathrm{cv}=\frac{\operatorname{sd}(x)}{\operatorname{mean}(x)} \times 100$

Where $\operatorname{mean}(\mathrm{x})=\frac{1}{n} \sum_{1}^{n} x_{i}$

$\operatorname{sd}(\mathrm{x})=\frac{1}{n} \sqrt{\sum\left(x_{i}-\operatorname{mean}(x)\right)^{2}}$

$\mathrm{cv}$ is a relative measure and is most suitable for comparing two series. The smaller result of $\mathrm{cv}$ gives more consistent than the others.

Coefficient of variation (CV) measure the consistency $\mathrm{cv}=\frac{\operatorname{sd}(x)}{\operatorname{mean}(x)} \times 100$

Figure 6 clearly shows the mean, sd and cv. 64.2 is Professor $\mathrm{cv}$ and it is smaller than the others that imply professor consistency is best then the others. Similarly Manager, Associate Professor, Student, Scientist also good.Consultant cv is high (186.3) then the others it imply inconsistent. That means some Consultant use large numbers of letter and some are use few.

\begin{tabular}{|c|c|c|c|c|c|c|c|c|}
\hline$=$ & Profession & letter & 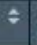 & mean.letter & $=1$ & sd.letter $\quad$ & ov & 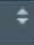 \\
\hline 1 & Assistant Professor & 4632 & & 62.6 & & 75.8 & 121.1 & \\
\hline 2 & Associate Professor & 523 & & 65.4 & & 62.8 & 96.0 & \\
\hline 3 & Consultant & 3996 & & 159.8 & & 297.7 & 186.3 & \\
\hline 4 & Engineer & 730 & & 42.9 & & 54.7 & 127.5 & \\
\hline 5 & Manager & 783 & & 34.0 & & 29.8 & 87.6 & \\
\hline 6 & Professor & 469 & & 46.9 & & 30.1 & 64.2 & \\
\hline 7 & Research Scholar & 7449 & & 99.3 & & 130.4 & 131.3 & \\
\hline 8 & Scientist & 710 & & 118.3 & & 123.5 & 104.4 & \\
\hline 9 & Student & 7891 & & 97.4 & & 101.6 & 104.3 & \\
\hline 10 & Teacher & 1956 & & 54.3 & & 70.9 & 130.6 & \\
\hline
\end{tabular}

Figure 6. Mean, SD and CV of Profession

\section{Assistant Professor}

Highlighted and bigger word shows most frequently use word of sharing opinion. And other small 


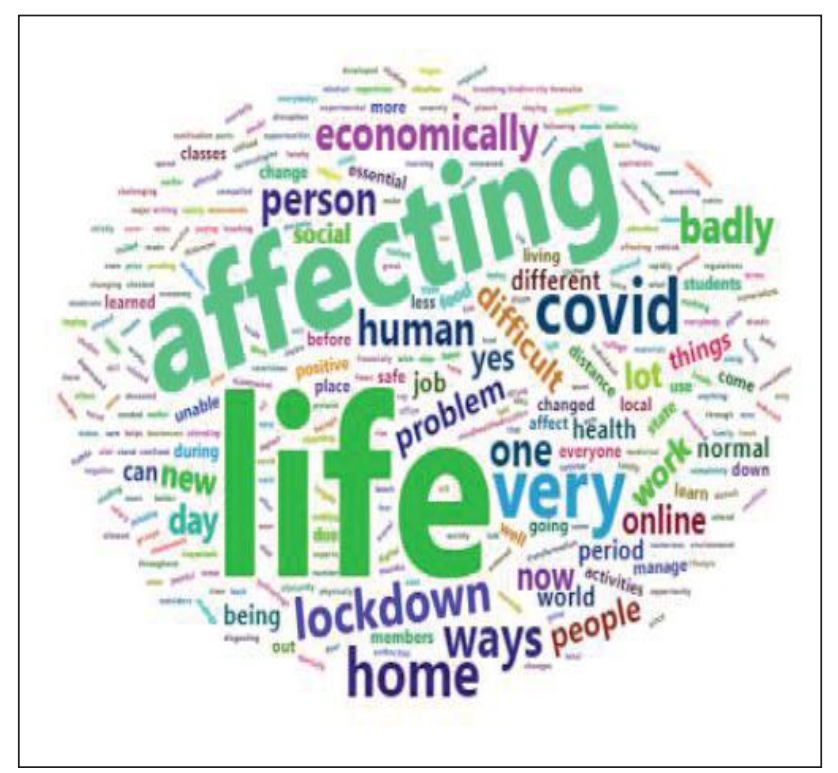

highlighted word shows the less frequently use word.

Figure 7. (Word Cloud Analysis of answers given by Assistant Professors against "How COVID 19 affecting your life?")

Assistant Professors use more frequently life, economically, lockdown, home, Covid, different, human, people, problem, social, work, world. Thiswords gives pre-images about the question how covis-19 affect in Assistant Professors life.

\section{Students}

Highlighted and bigger word shows most frequently use word of sharing opinion. And othersmall highlighted word shows the less frequently use word. Students use more frequently life, economically, lockdown, health, home, future, daily,online, activities, exams, staying, lockdown, opportunities, work, education, mental,pandemic. This words gives pre-images about the question how covis-19 affect in Students life.

\section{Research Scholar}

Highlighted and bigger word shows most frequently use word of sharing opinion. And other small highlighted word shows the less frequently use word.

Research Scholar use more frequently research, life, affecting, Ph.D., lockdown, health, home, family, work, lock, mental, pandemic, opportunities, lab, positive, global.

This words gives pre-images about the question how covis-19 affect in Research Scholar life.

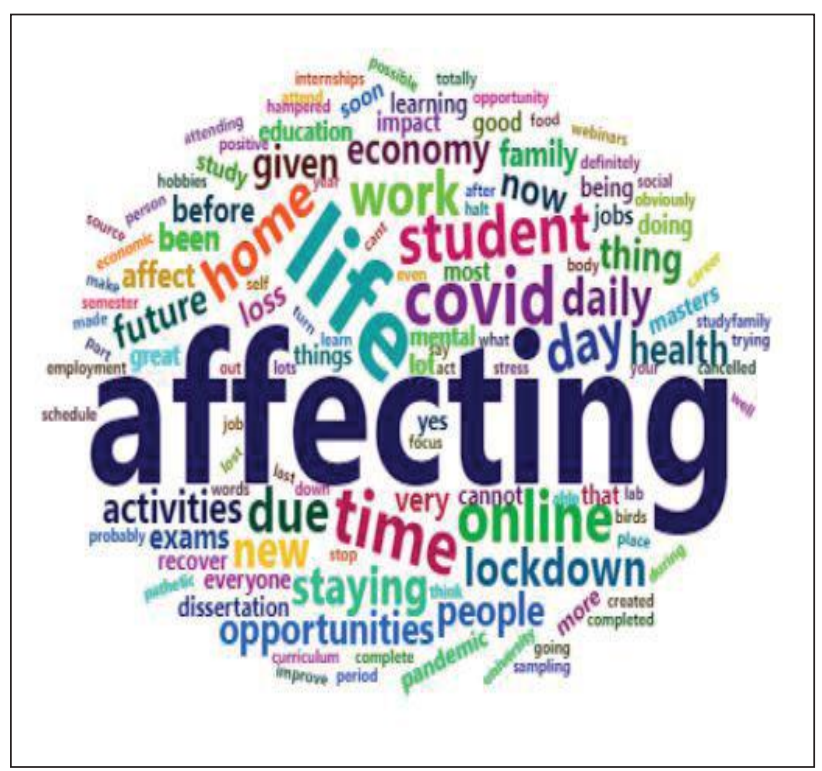

Figure 8. (Word Cloud Analysis of answers given by Students against "How COVID 19 affecting your life?")

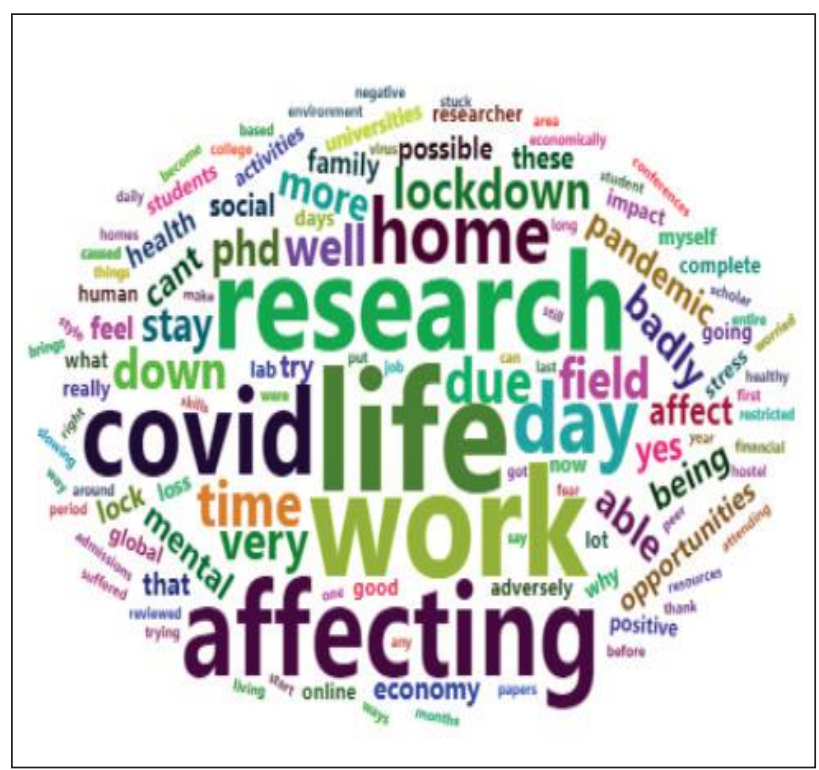

Figure 8. (Word Cloud Analysis of answers given by Research Scholars against "How COVID 19 affecting your life?")

\section{Consultant}

Highlighted and bigger word shows most frequently use word of sharing opinion. And other small highlighted word shows the less frequently use word. Consultant use more frequently life, affecting, financial, situation, life, job, unemployed, change, opportunity, increase, family, country, business, working, home.

Thesewords are giving pre-images about the question 


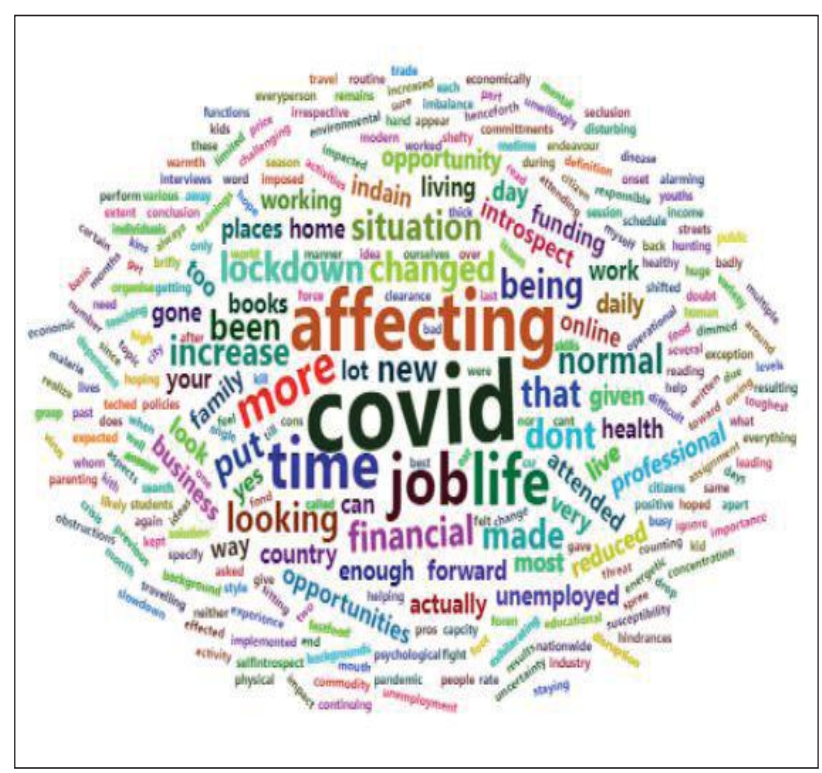

Figure 9. (Word Cloud Analysis of answers given by Consultants against "How COVID 19 affecting your life?")

how COVID-19 affect in consultant life.

\section{Conclusion}

This survey particularly indicates the different difficulties and challenges towards environmental education as well as environmental employments while the natural environment is healing up during this pandemic period. This study paved way to draw attention of the government and policy makers.

\section{Recommendations:}

In this article we have discussed about the recent scenario of educational and employment on the environmental sector.As per the analyzed data, following recommendations have been highlighted.

- Follow government rules and regulations to combat COVID-19 and maintain personal hygiene.
- Follow the strategies to reframe NEGATIVE THOUGHTSto keep well mental health.

- Don't be depressed, share your emotions with family / friends / close persons and don't be judgmental while anyone sharing their emotions with you - be a good listener.

- Keep continuation with daily basic physical exercise and eat healthy - natural immune booster.

- Be positive about innovative business idea along with startups, be self dependent and contribute in country economy.

Acknowledgement: The authors are thankful to Voice of Environment (VoE) Guwahati, Assam, India (Environmental Organisation) and Indian School of Complementary Therapy and Allied Sciences (ISCTAS) for the survey research study and support from VoE members for the data collection and analysis work; and Dr. Vimala Raghavan (Associate Professor at CNR, VIT Vellore, India) and Prof. Andrews Nirmala Grace (Director at CNR, VIT Vellore, India) for continuously encouraging the team.

Ethical Clearances: Not Applicable for this article from the side of host institute/organization.

Contribution of Authors: Data gathering and idea owner of this study: MC, SG, AC; Study design: MC, SG, AC, SM; Data Analysis: SM; Writing and submitting manuscript:SG, $\mathrm{AC}$; Editing and approval of final draft: MC, SG; Visualization:AC; Proofreading: MC, SG

Funding: This survey doesn't receive any financial support from any funding agencies.

Conflict of Interest: The authors declare no conflict of interest. 


\section{References:}

1. Srivatsan R, Indi PN, Agrahari S, Menon S, Ashok SD. Machine learning based prognostic model and mobile application software platform for predicting infection susceptibility of COVID-19 using healthcare data. Research on Biomedical Engineering. 2020;12:1-2. https://doi.org/10.1101/2020.10.09.20165431

2. Haque M. Combating covid-19: a coordinated efforts of healthcare providers and policy makers with global participation are needed to achieve the desired goals. Bangladesh Journal of Medical Science. (Special issue on Covid19) 2020:S01-S05. .https://doi.org/10.3329/ bjms.v19i0.47610

3. ALAM, Ahmed Nawsher et al. Review of the Corona Viruses Causing Acute Respiratory Syndrome and COVID-2019 (COVID-19) Pandemic. International Journal of Human and Health Sciences (IJHHS). 2020;5 (2):139-147. doi:http://dx.doi.org/10.31344/ijhhs. v5i2.250.

4. MOHD ZAINI, Ahmad Faidhi; RASHID, Aneesa Abdul. The COVID-19 pandemic and positive reflections on Ramadhan. International Journal of Human and Health Sciences (IJHHS). 5 (2): 191-193. https://doi. org/10.31344/ijhhs.v5i2.258

5. MOJUMDER, Dipayan et al. COVID-19 Detection by Salivary Analysis: Easy and Reliable Approach in Massive Outbreak. International Journal of Human and Health Sciences (IJHHS). 2020; 5 (1):7-11. doi:http:// dx.doi.org/10.31344/ijhhs.v5i1.224

6. Khan MG, Yezdani U, Chakravorty A, Shukla T. Efforts and Challenges paved by India to confront of Corona Virus (COVID-19). Bangladesh Journal of Medical Science. (Special issue on Covid19). 2020:S88-S92. https://doi.org/10.3329/bjms.v19i0.48198

7. SSAKA, Mustafa et al. Community use of masks as a preventive measure for Covid-19 in Kabale district of Uganda. International Journal of Human and Health Sciences (IJHHS). 2020; 5 (2): 267-270. https://doi.org/10.31344/ijhhs.v5i2.274

8. PARIKESIT, Arli Aditya; RATNASARI, Nanda RizqiaPradana; ANUROGO, Dito. Application of Artificial Intelligence-Based Computation in the Health Sciences to Ward off the COVID-19 Pandemic. International Journal of Human and Health Sciences (IJHHS). 2020; 5 (2): 177-184. https://doi.org/10.31344/ijhhs.v5i2.256

9. Ankaralı, H., Erarslan, N., Pasin, Özge, \& Mahmood, A. K. (2020). Modeling and Short-Term Forecasts of Indicators for COVID-19 Outbreak in 25 Countries at the end of March. Bangladesh Journal of Medical Science. (Special issue on Covid19) 2020:S6-S20. https://doi. org/10.3329/bjms.v19i0.47611

10. https://www.who.int/news/item/13-10-2020-impact-ofcovid-19-on-people's-livelihoods-their-health-and-ourfood-systems

11. ALIMOGLU, Orhan et al. What the COVID-19 pandemic means for sub-Saharan African countries. International Journal of Human and Health Sciences (IJHHS). 2020; 5 (1): 127-128. https://doi.org/10.31344/ijhhs.v5i1.248

12. https://www.unicef.org/coronavirus/keeping-worldschildren-learning-through-covid-19

13. Gupta N, Pandey S, Anshu A. Innovative Anatomy assessment methods in COVID-19 Pandemic: statistical observations and students viewpoints. Bangladesh Journal of Medical Science. (Special issue on Covid19). 2020:S21-S27. https://doi.org/10.3329/bjms.v19i0.47831

14. Haque M, Islam S, Iqbal S, Urmi UL, Kamal ZM, Rahman A, Kamal M, Haque M, Jahan I, Islam Z, Hossain MM. Availability and price changes of potential medicines and equipment for the prevention and treatment of COVID-19 among pharmacy and drug stores in Bangladesh; findings and implications. Bangladesh Journal of Medical Science. (Special issue on Covid19) 2020:S36-S50. https://doi.org/10.3329/bjms.v19i0.48106

15. Rahali K, Abidli Z, Khohmimidi A, Elhamzaoui M, Seghiri R, Jabari K, Aouane E, Chaouch A. Ibn Tofail's University students' satisfaction evaluation towards distance learning and its impacts on the students' mental health during the Covid 19 Confinement. Bangladesh Journal of Medical Science.(Special issue on Covid19) 2020:S51-S57. https://doi.org/10.3329/bjms.v19i0.48166

16. Lebkiri N, Abidli Z, Jadda S, Mokhtari A, Soulaymani A. Impact of containment type on Covid-19 propagation in Morocco using the SIR model. Bangladesh Journal of Medical Science. (Special issue on Covid19) 2020:S58-S65. https://doi.org/10.3329/bjms.v19i0.48167

17. Ashiq K, Ashiq S, Bajwa MA, Tanveer S, Qayyum M. Knowledge, attitude and practices among the inhabitants of Lahore, Pakistan towards the COVID-19 pandemic: an immediate online based cross-sectional survey while people are under the lockdown. Bangladesh Journal of Medical Science. (Special issue on Covid19)2020;:S69-S76. https://doi.org/10.3329/bjms.v19i0.48169

18. FAROOK, Taseef; JAMAYET, Nafij Bin; ALAM, Mohammad Khursheed. Fatal mistake: Dentistry the next epicenter of SARS-CoV-2 spread. International Journal of Human and Health Sciences (IJHHS). 2020;4(4):235236. https://doi.org/10.31344/ijhhs.v4i4.207 